\title{
Expression and function of miR-155 in rat synovial fibroblast model of rheumatoid arthritis
}

\author{
HEWEI LI ${ }^{1}$, PING LIU ${ }^{1}$, YANLIN GONG ${ }^{2}$, JIALI LIU ${ }^{1}$ and FENG RUAN ${ }^{1}$ \\ ${ }^{1}$ Department of Orthopedics, Liyuan Hospital Affiliated to Tongji Medical College of Huazhong University of \\ Science and Technology, Wuhan, Hubei 430077; ${ }^{2}$ Department of Endocrinology, \\ Wuhan No. 1 Hospital, Wuhan, Hubei 430022, P.R. China
}

Received October 10, 2017; Accepted March 1, 2018

DOI: $10.3892 /$ etm.2019.7581

\begin{abstract}
Rheumatoid arthritis (RA) is a common autoimmune disease characterized by joint synovial inflammation and is a challenge for researchers and clinicians. MicroRNAs (miRNAs/miRs) represent a group of small non-coding RNA molecules that post-transcriptionally regulate mRNA expression and are involved in various diseases, including cancer, autoimmune and metabolic diseases, as well as neurological disorders. In the present study, various experiments were performed to investigate the effects and underlying mechanism of miR-155 in RA using rat synoviocytes induced by lipopolysaccharide (LPS) to model rheumatoid arthritis. It was revealed that synovial fibroblasts exhibited significantly higher miR-155 mRNA levels than the control group. Compared with the RA group, the viability of synovial fibroblasts was significantly decreased in the miR-155 mimics + RA group, but markedly increased in the miR-155 inhibitor + RA group. Compared with that in the RA + $\mathrm{NC}$ mimic or RA + NC inhibitor groups, the apoptosis of synovial fibroblasts increased significantly in the miR-155 mimics + RA group, but was significantly decreased in the miR-155 inhibitor + RA group. The miR-155 mimics + RA group exhibited higher expression levels of $\beta$-catenin, matrix metalloproteinase 7 and cyclin D1 compared with the miR-155 inhibitor + RA group, and the glycogen synthase kinase protein levels was lower compared with the miR-155 inhibitor + RA group. In brief, it was inferred that the Wnt signaling pathway is involved in the miR-155-associated inhibition of RA synovial fibroblast viability and induction of cell apoptosis. Inhibition of miR-155 may be an effective
\end{abstract}

Correspondence to: Dr Feng Ruan, Department of Orthopedics, Liyuan Hospital Affiliated to Tongji Medical College of Huazhong University of Science and Technology, 18 Guangrong Village, Wuhan, Hubei 430077, P.R. China

E-mail:rf001m5@sina.com

Key words: rheumatoid arthritis, microRNA-155, synovial fibroblasts, viability, apoptosis, cell cycle treatment for RA through regulation of the Wnt signaling pathway to reduce cell apoptosis and enhance cell viability.

\section{Introduction}

Rheumatoidarthritis(RA)is a chronic autoimmune inflammatory disease mainly characterized by a systemic autoimmune disorder, cartilage degradation and synovial inflammation (1). Several risk factors, including heredity, infection and gonadal hormone contribute to RA (2). Synovial tissue in patients with RA features the production of inflammatory cytokines, including tumor necrosis factor $\alpha$ and interleukin- $1 \beta$ by macrophages, and $\mathrm{T}$ and $\mathrm{B}$ cells, and inhibiting these cytokines may ameliorate the clinical symptoms of RA (3). However, the mechanisms underlying the genesis and progression of RA remain elusive, and no appropriate therapeutic strategies have been developed to cure this disease (4). Aberrant gene expression in RA is associated with synovial inflammation; however, the precise mechanisms that lead to altered gene expression in RA remain poorly understood.

MicroRNAs (miRNAs/miRs) are small noncoding RNAs of 22-24 nucleotides in length that regulate target gene expression by binding to the 3'-untranslated region, and miRNAs have roles in biological processes, including cell proliferation, apoptosis and differentiation (5). Hundreds of miRNAs have been detected in various organisms and most of them have an essential role in regulating gene expression through targeting mRNA translation or inducing mRNA cleavage (6). A large number of studies have revealed that miRNAs, including miR-155, miR-146, miR-132 and miR-16, are involved in RA. miR-155 is upregulated in the synovial membrane and synovial fluid macrophages from patients with RA (7). miR-146 appears to be associated with the inflammatory response in RA (8). miR-16 was reported to be overexpressed in the peripheral blood mononuclear cells of RA patients (8). However, the effects and mechanisms of miRNA gene expression in RA are not well understood.

The present study evaluated the expression levels of miR-155, miR-203 and miR-146 in rat synovial fibroblasts of control and RA groups. The aim of the present study was to evaluate the effects of miRNA on synovial fibroblast viability, apoptosis and the cell cycle, and the underlying mechanisms, including inflammatory signaling pathways in RA, were also investigated. 


\section{Materials and methods}

Animals. A total of 3 healthy male Sprague Dawley rats (age, 8 weeks; weight, 200 $\pm 20 \mathrm{~g}$ ) were purchased from the Laboratory Animal Center of Huangzhong University of Science and Technology (Wuhan, China). The experimental rats had been bred under constant conditions, including $55-60 \%$ humidity at $23 \pm 2^{\circ} \mathrm{C}$ and were provided with water and food ad libitum. All animal experimental procedures were approved by the Institutional Animal Care and Use Committee at Tongji Hospital, Tongji Medical College, Huazhong University of Science and Technology.

Isolation and culture of synovial fibroblasts. Rat knee joint synovial tissue was cut into small fragments and digested in Dulbecco's modified Eagle's medium (DMEM) containing $1 \mathrm{mg} / \mathrm{ml}$ collagenase II (both Thermo Fisher Scientific, Inc. Waltham, MA, USA) at $37^{\circ} \mathrm{C}$ for $2 \mathrm{~h}$. The synovial fibroblasts were collected after centrifugation and maintained in DMEM containing $5 \mathrm{mmol} / \mathrm{l}$ glucose and $10 \%$ fetal bovine serum (FBS; Thermo Fisher Scientific, Inc.) in a humidified atmosphere containing $5 \% \mathrm{CO}_{2}$ at $37^{\circ} \mathrm{C}$. The cells were passaged when they reached confluency. The fourth generation of cells was used for the experiment. Microscopy images displaying the cell morphology are presented in Fig. 1A. The purity of the cells was tested using immunofluorescence with rabbit anti-vimentin (cat. no. ab45939; 1:100 dilution; Abcam, Cambridge, MA, USA) and mouse anti-CD68 (cat. no. ab125212; 1:50 dilution) antibodies. Following blocking in 5\% bovine serum albumin (BSA; Sigma-Aldrich; Merck KGaA, Darmstadt, Germany) for $1 \mathrm{~h}$ at room temperature, cells were incubated with anti-vimentin and -CD68 primary antibodies for $1 \mathrm{~h}$ at room temperature. Cells were washed with PBS, incubated for $1 \mathrm{~h}$ at room temperature with AlexaFluor ${ }^{\circledR}$ 488-conjugated secondary antibodies (cat. no. ab150081; 1:500; Abcam) and incubated for $1 \mathrm{~h}$ at room temperature with nuclear DNA was labeled in blue with DAPI.

Cell transfection and reagents. Synovial fibroblasts were divided into a negative control + RA group, miR-155 mimics + RA group and a miR-155 inhibitor + RA group. Cells were cultured until $60-70 \%$ confluent and then transfected with miR-155 mimics, miR-155 inhibitor or negative control (NC; all GenePharm S.A. Pallini, Greece) by using Lipofectamine ${ }^{\circledR} 2000$ (Invitrogen; Thermo Fisher Scientific, Inc., Waltham, MA, USA) according to the manufacturer's protocol. After $48 \mathrm{~h}$, the synovial fibroblasts were harvested for further experiments. Lipopolysaccharide (LPS; 1 ng/ml; Sigma-Aldrich; Merck KGaA, Darmstadt, Germany) was added to synovial fibroblasts for $24 \mathrm{~h}$ prior to transfection. The following sequences were used: miRNA inhibitor NC, 5'-CAGUACUUUUGUGUAGUACAA-3'; miRNA-155-5P inhibitor, 5'-ACCCCUAUCACAAUUAGCAUUAA-3'; miRNA mimics NC sense, 5'-UUCUCCGAACGUGUCACGUTT-3' and anti-sense, 5'-ACGUGACACGUUCGGAGA ATT-3'; miRNA-155-5P mimics sense, 5'-UUAAUGCUAAUUGUG AUAGGGGU-3' and anti-sense, 5'-CCCUAUCACAAUUAG CAUUAAUU-3'.

MTT assay. Cell viability was measured using an MTT assay. Cells were seeded into 96-well plates at a density of $1 \times 10^{5}$ cells/well and then stimulated with LPS. After transfection with miRNA inhibitor, miRNA mimics or negative control for $48 \mathrm{~h}, 20 \mu \mathrm{l}$ MTT (5 mg/ml; Sigma-Aldrich; Merck KGaA) was added to each well, followed by incubation for $4 \mathrm{~h}$. At the end of the incubation period, the medium was removed and $150 \mu \mathrm{l}$ dimethylsulfoxide was added to each well. After shaking at low speed for $10 \mathrm{~min}$, the absorbance of the dye that had formed was measured at a wavelength of $490 \mathrm{~nm}$.

Cell apoptosis assay. Apoptosis analysis was performed with the Annexin V-fluorescein isothiocyanate (FITC)/propidium iodide (PI) flow cytometry kit (BD Biosciences, Franklin Lakes, NJ, USA) according to the manufacturer's instructions. After the different treatments, cells were washed three times with ice-cold PBS and re-suspended in $200 \mu \mathrm{l}$ binding buffer at a concentration of $1 \times 10^{6}$ cells $/ \mathrm{ml}$. Subsequently, $10 \mu \mathrm{l}$ Annexin V-FITC and $10 \mu \mathrm{l}$ PI were added and cells were incubated for $30 \mathrm{~min}$ at $4^{\circ} \mathrm{C}$ in the dark. Finally, $300 \mu \mathrm{l}$ binding buffer was added and cells were analyzed by flow cytometry (Cytomics FC 500; Beckman Coulter, Brea, CA, USA) within $1 \mathrm{~h}$.

Cell cycle assay. Cells were washed thrice with ice-cold PBS and then fixed with $70 \%(\mathrm{v} / \mathrm{v})$ ethanol at $-70^{\circ} \mathrm{C}$ for $1 \mathrm{~h}$. Following washing with PBS, a staining solution $[10 \mathrm{mmol} / 1$ Tris (pH 7.0), 0.1\% Nonidet P-40, $1 \mathrm{mmol} / 1 \mathrm{NaCl}, 0.7 \mu \mathrm{g} / \mathrm{ml}$ ribonuclease $\mathrm{A}$ and $5 \mu \mathrm{g} / \mathrm{ml}$ propidium iodide] was added to the cells. After incubation for $30 \mathrm{~min}$ in the dark, the cellular DNA content was determined using flow cytometry.

RNA extraction and reverse transcription-quantitative polymerase chain reaction $(R T-q P C R)$. Total RNA was isolated from cells by using TRIzol reagent (Invitrogen; Thermo Fisher Scientific, Inc.), and complementary (c)DNA was generated using a PrimeScript II 1st strand cDNA Synthesis kit (Takara Bio, Inc., Otsu, Japan). Subsequently, cDNA sequences were amplified with SYBR Premix Ex Taq ${ }^{\mathrm{TM}}$ (Takara Bio, Inc.) with specific primers listed in Table I. The thermocycling conditions consisted of an initial step of $3 \mathrm{~min}$ at $95^{\circ} \mathrm{C}$, followed by 35 cycles of $95^{\circ} \mathrm{C}$ for $5 \mathrm{sec}, 56^{\circ} \mathrm{C}$ for $10 \mathrm{sec}$ and $72^{\circ} \mathrm{C}$ for $25 \mathrm{sec}$. PCR products were analyzed using an optimized the $2^{-\Delta \Delta \mathrm{Cq}}$ method (9).

Statistical analysis. SPSS 18.0 statistical software (SPSS, Inc., Chicago, IL, USA) was applied to analyze the data. Values are expressed as the mean \pm standard deviation. Significant differences between groups were assessed using Student's t-test or one-way analysis of variance followed by Duncan's test. $\mathrm{P}<0.05$ was considered to indicate a statistically significant difference.

\section{Results}

Phenotypic characteristics of synovial fibroblasts. Synovial fibroblasts were isolated from rats. After reaching confluence, cells were passaged 4 times, and the phenotypic characteristics of the cells were observed. The cells had fusiform or cylindrical shapes and the nuclei were ovoid in the cells (Fig. 1A). The synovial fibroblast cultures were negative for CD68 and positive for vimentin (Fig. 1B). 
Table I. Primers used for polymerase chain reaction.

\begin{tabular}{lll}
\hline Name & \multicolumn{1}{c}{ Forward primer $\left(5^{\prime}-3^{\prime}\right)$} & \\
\hline miR-155 & TTAATGCTAATCGTG & CTCAACTGGTGTCGTGGAGTCGGCAATTCAGTTGAGACCCCTAT \\
miR-203 & AGTGGTTCTTAACAGTT & CTCAACTGGTGTCGTGGAGTCGGCAATTCAGTTGAGAACTGTTG \\
miR-16 & TAGCAGCACGTAAA & CTCAACTGGTGTCGTGGAGTCGGCAATTCAGTTGAGCGCCAATA \\
$\beta$-catenin & AATGGCTTGGAATGAGA & AGTGAAAAGAACGGTAG \\
GSK-3 $\beta$ & CGGGATCCGCCACCATGTCG & CCCCCCAGGAATTCTCAGGTAGAGTTGGAGGCTGA \\
& GGGCGACCGAGA & \\
MMP-7 & CCAAATAGCCCAAAATGGACTTC & TGTAATATGCGGTAAGTCTCGAGTATATG \\
CyclinD1 & TGTTCGTGGCCTAAGATGAAG & GGAAGTGTTCGATGAAATCGTG \\
GAPDH & CCATCAATGACCCCTTCATTG & CATGGGTGGAATCATATTGGAAC \\
\hline
\end{tabular}

GSK, glycogen synthase kinase; MMP, matrix metalloproteinase; miR, microRNA.

A
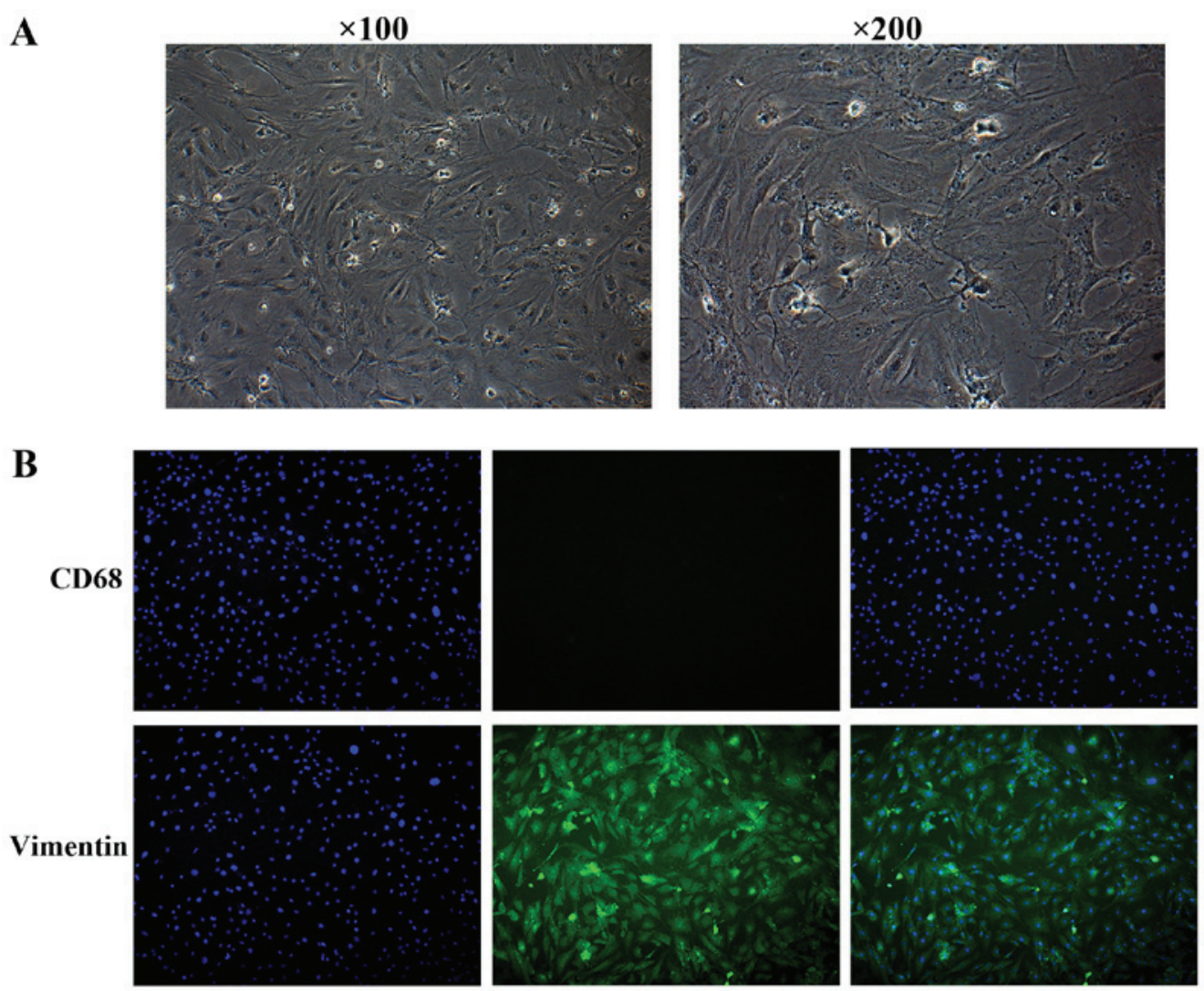

Figure 1. Cell morphology and phenotypic characteristics of synovial fibroblasts. (A) Cell morphology was detected by optical microscopy (magnification, $\mathrm{x} 100$ or x200). (B) The expression of CD68 and vimentin was detected by immunofluorescence microscopy. Magnification, $\mathrm{x} 200$. Nuclei were stained in blue using DAPI (left-hand panel), immunostaining is presented in green (middle panel) and the right-hand panel displays a merge of the two.

Effect of LPS treatment on cell viability. A number of studies have suggested that LPS and its pattern recognition receptor, Toll-like receptor 4 , have a critical role in the development of RA $(10,11)$. In the present study, cells were stimulated with LPS at a concentration of 1,10 or $100 \mathrm{mg} / 1$ for 24,48 or $72 \mathrm{~h}$. The results indicated that the cell viability was reduced in a doseand time-dependent manner (Fig. 2). In order to ensure that LPS induces an inflammatory response in synovial fibroblasts, while minimizing the adverse impact of LPS in the subsequent experiments, the conditions of $1 \mathrm{mg} / \mathrm{l}$ and $24 \mathrm{~h}$ were selected to induce the RA model in the present study (12).
miR-155, miR-203 and miR-16 RNA expression in synovial fibroblasts. The mRNA expression levels of miR-155, miR-203 and miR-16 were analyzed by RT-qPCR in control and RA cells. As presented in Fig. 3, miR-155 and miR-16 expression levels were significantly higher in the RA group than in the control group, and miR-155 levels were much higher than miR-16 levels in the RA group. miR-155 was therefore selected for further study.

miR-155 regulates the viability of synovial fibroblasts with $R A$. The following five groups were set up: Control, RA + mimics 


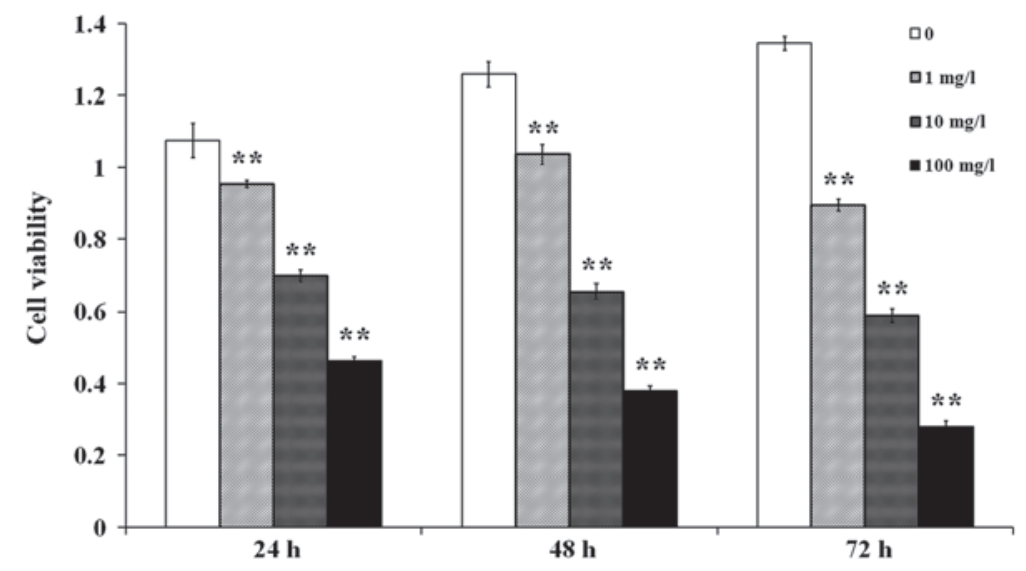

Figure 2. Effect of LPS on the viability of synovial fibroblasts. Cells were treated with LPS at concentrations of 1,10 and $100 \mathrm{mg} / \mathrm{l}$ for 24,48 and $72 \mathrm{~h}$. ${ }^{* *} \mathrm{P}<0.01$ vs. control group. LPS, lipopolysaccharide.

NC (LPS stimulation and transfection of mimics NC), RA + inhibitor NC (LPS stimulation and transfection of inhibitor NC), RA + mimics 155 (LPS stimulation and transfection of miR-155 mimics) and RA + inhibitor 155 (LPS stimulation and transfection of miR-155 inhibitor). The results indicated that the cell viability in the RA + mimics NC and RA + inhibitor $\mathrm{NC}$ groups was lower than that in the control group (Fig. 4). Compared with that in the RA + mimics NC and RA + inhibitor NC groups, the RA + mimics 155 group had a reduced cell viability, but the RA + inhibitor 155 group had a significantly elevated cell viability (Fig. 4). Taken together, miR-155 inhibits the viability of synovial fibroblasts with RA.

miR-155 regulates apoptosis of synovial fibroblasts with $R A$. Cell apoptosis was measured by Annexin V-FITC/PI staining and flow cytometric analysis. As presented in Fig. 5, the percentages of apoptotic cells in the RA + mimics $\mathrm{NC}$ and $\mathrm{RA}+$ inhibitor NC groups were significantly higher than those in the control group. The RA + mimics 155 group had a markedly elevated percentage of apoptotic cells but the RA + inhibitor 155 group had a significantly decreased apoptotic rate (Fig. 5). These results suggest that miR-155 increased the apoptosis of synovial fibroblasts with RA.

miR-155 regulates the cell cycle of synovial fibroblasts with $R A$. The cell cycle was measured by flow cytometry following PI staining. As presented in Fig. 6, a significant cell cycle arrest in $\mathrm{G}_{1}$ phase was detected in the RA + mimics $\mathrm{NC}$, $\mathrm{RA}+$ inhibitor NC and RA + mimics 155 groups, while this arrest was abrogated in the RA + inhibitor 155 group and the cell cycle progression was restored partially compared to the $\mathrm{RA}+$ mimics 155 group. These results indicated that miR-155 induced cycle arrest in $\mathrm{G}_{1}$ phase in synovial fibroblasts with RA.

miR-155 regulates Wnt effector protein expression in synovial fibroblasts with $R A$. The effector proteins of the Wnt signaling pathway were quantified by RT-qPCR. As presented in Fig. 7, the expression levels of $\beta$-catenin, matrix metalloproteinase (MMP)7 and cyclin D1 in the RA + mimics NC and $\mathrm{RA}+$ inhibitor NC groups were higher than those in the control group, while the glycogen synthase kinase (GSK)-3 $\beta$ expression

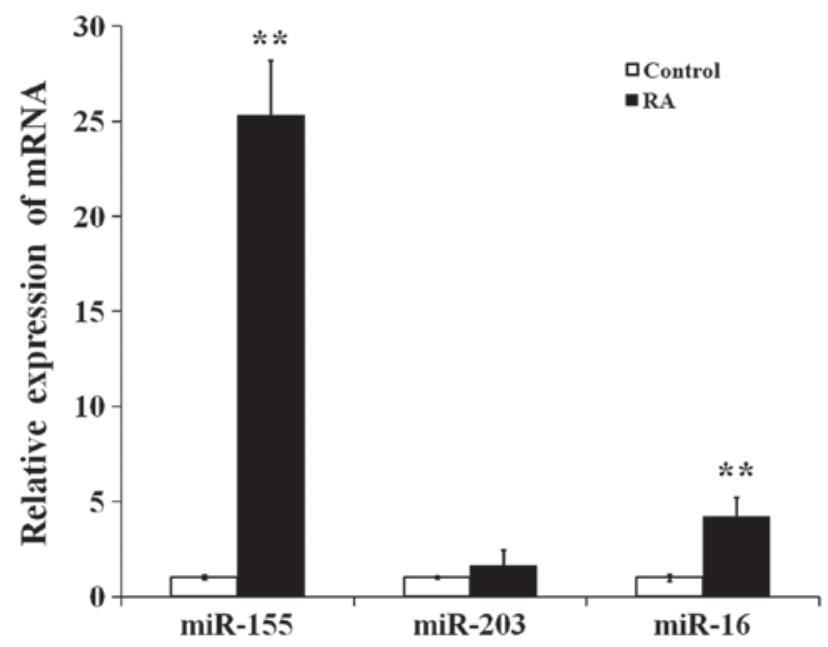

Figure 3. Expression of miR-155, miR-203 and miR-16 in synovial fibroblasts. The levels of miR-155, miR-203 and miR-16 in normal synovial fibroblasts and those induced with lipopolysaccharide to model RA were detected by reverse transcription-quantitative polymerase chain reaction. ${ }^{* *} \mathrm{P}<0.01$ vs. control group. miR, microRNA; RA, rheumatoid arthritis.

in the RA + mimics $\mathrm{NC}$ and $\mathrm{RA}+$ inhibitor $\mathrm{NC}$ groups was lower than that in the control group. In the RA + mimics 155 group, the expression levels of $\beta$-catenin, MMP7 and cyclin D1 were significantly elevated compared with those in the $\mathrm{NC}+\mathrm{RA}$ groups, but those in the RA + inhibitor 155 group were reduced. Conversely, the expression of GSK-3 $\beta$ was significantly decreased in the RA + mimics 155 group, but increased in the RA + inhibitor 155 group compared with that in the NC + RA groups.

\section{Discussion}

Accumulating evidence indicates that synovial inflammation contributes to the progression of RA $(13,14)$. The presence of synovitis in a significant proportion of patients with primary RA has been increasingly recognized. Based on this observation, further studies have implicated joint inflammation and synovitis in the pathogenesis of RA $(15,16)$. By regulating various cellular processes, including cell proliferation, immune responses, inflammation, apoptosis and cell signaling, 


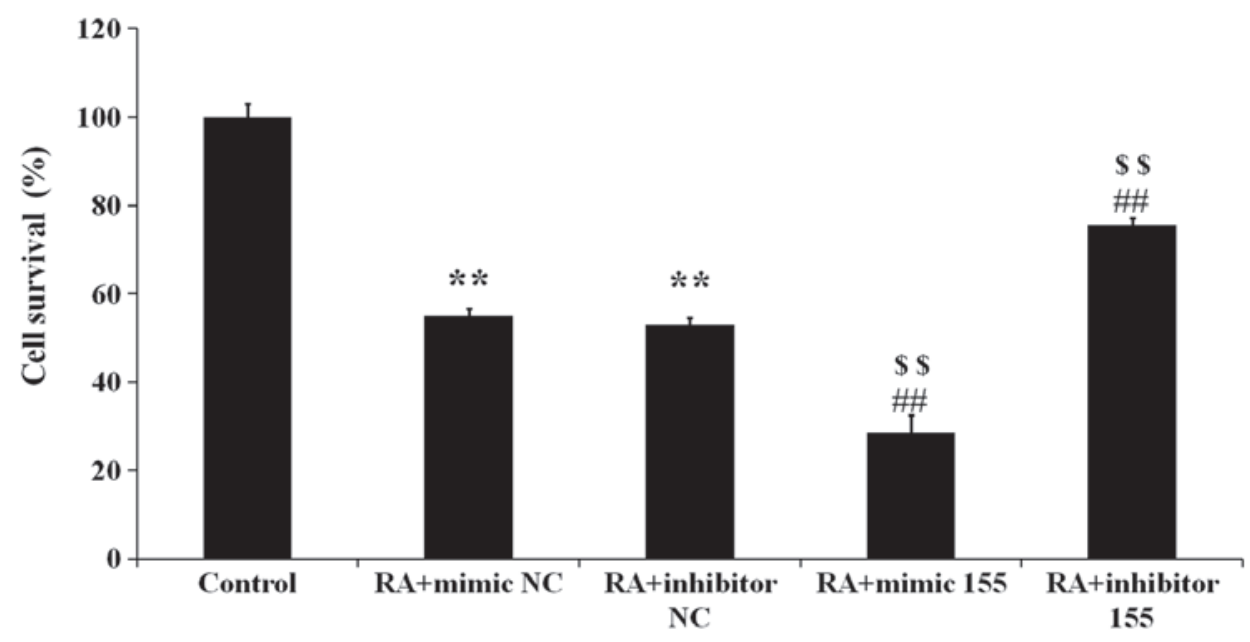

Figure 4. Effect of miR-155 on the viability of LPS-induced synovial fibroblasts. The percentage of surviving cells was detected by an MTT assay. ${ }^{* *} \mathrm{P}<0.01$ vs. control group; ${ }^{\# \#} \mathrm{P}<0.01$ vs. $\mathrm{RA}+\operatorname{mimic} \mathrm{NC} ;{ }^{\$ \$} \mathrm{P}<0.01$ vs. $\mathrm{RA}+$ inhibitor NC. miR, microRNA; RA, rheumatoid arthritis; NC, negative control; mimic 155, miR-155 mimics.
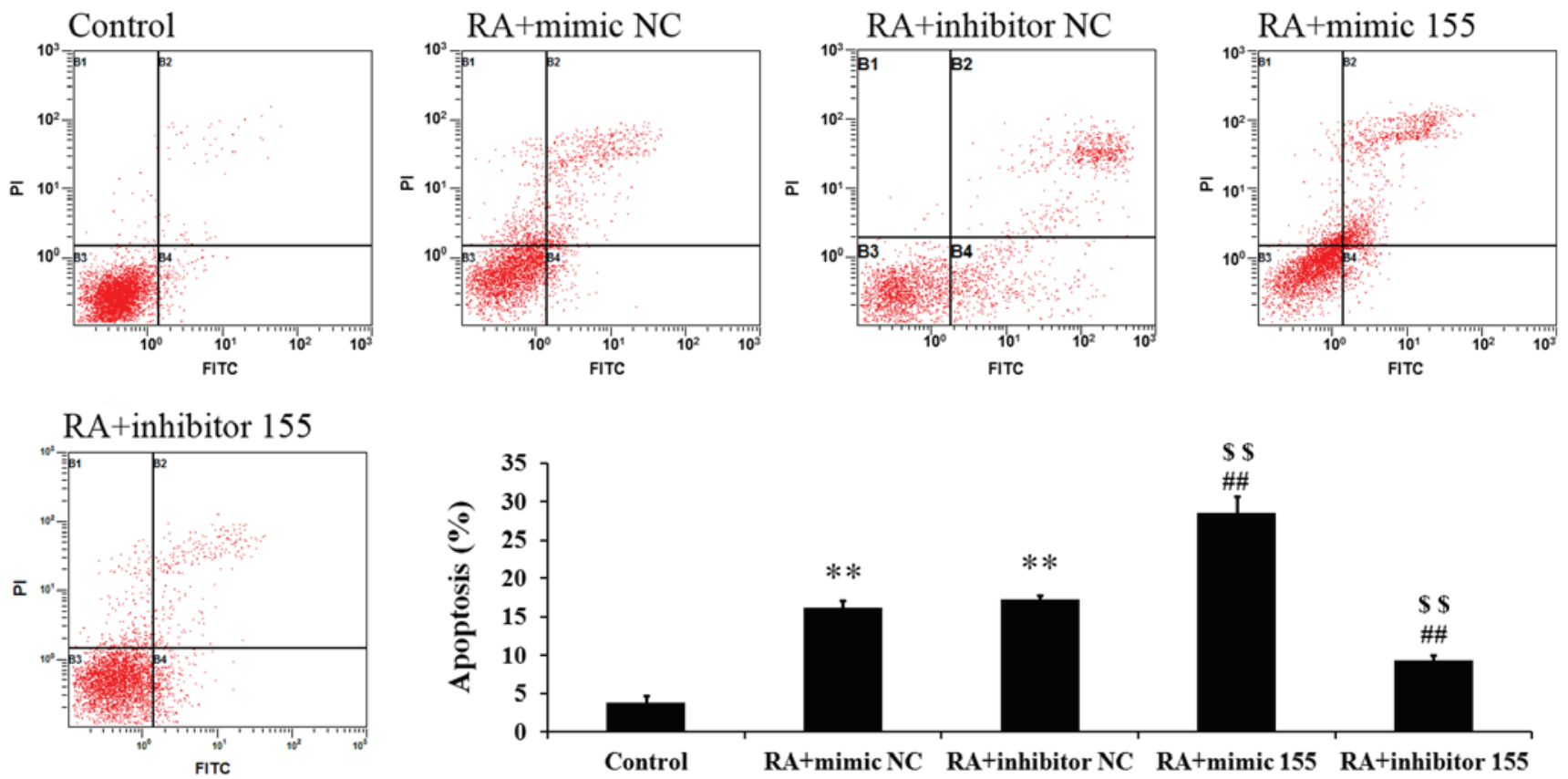

Figure 5. Effect of miR-155 on the apoptosis of LPS-induced synovial fibroblasts. The percentage of apoptotic cells was detected by flow cytometry. Quadrants: $\mathrm{B} 1$, necrotic cells; B2, apoptotic cells; B3, live cells; B4, early apoptotic cells. ${ }^{* * *} \mathrm{P}<0.01$ vs. control group; ${ }^{\# / \mathrm{P}}<0.01 \mathrm{vs}$. RA + mimic $\mathrm{NC}$; ${ }^{\$ \$} \mathrm{P}<0.01 \mathrm{vs.} \mathrm{RA}+$ inhibitor NC. miR, microRNA; RA, rheumatoid arthritis; NC, negative control; FITC, fluorescein isothiocyanate; PI, propidium iodide; mimic 155, miR-155 mimics.

miRNAs have an important role in the development and progression of various diseases. Diverse miRNA expression profiles (such as the deregulation of miRNA expression) were identified as crucial small-molecular regulators in severe joint diseases, including osteoarthritis and RA $(7,14,17)$. The present study mainly investigated the role of miR-155 in RA.

RA synoviocytes are considered as the effector cells of cartilage and bone destruction (18). Joint synovial cells are divided into two cell types: Macrophage-like synoviocytes (MLS) and fibroblast-like synoviocytes (FLS). Among them, MLS are negative for vimentin and positive for CD68, while FLS are negative for CD68 and positive for vimentin (19). Synovial fibroblasts have been reported to have a crucial role in RA pathogenesis (20). In the present study, synovial fibroblasts were isolated and identified as FLS, not MLS. LPS initiates the signaling cascades that cause inflammation and finally result in RA (21). Therefore, the present study used LPS-stimulated cells as the RA model to evaluate the effect of miR-155 on RA development.

miR-155 and miR-16 have been reported to be associated with RA $(22,23)$. Jin et al $(24)$ reported that overexpression of miR-155 in synovial fluid mononuclear cells leads enhanced proinflammatory factors. The results of the present study indicated that miR-155 expression exhibited a marked difference between the control and RA groups, indicating the crucial role of miR-155 in RA. In a previous study, miR-155 was induced in response to inflammatory stimuli and acted as a positive regulator of inflammation in RA in vivo, indicating 
Control

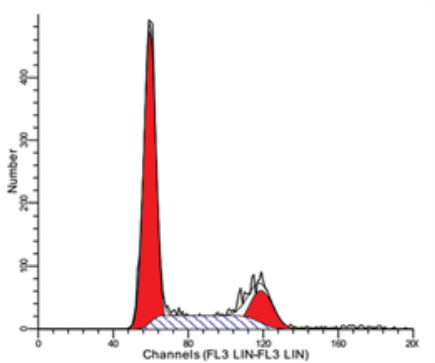

RA+inhibitor 155

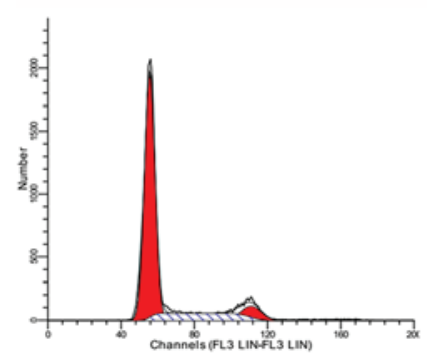

RA+mimic NC
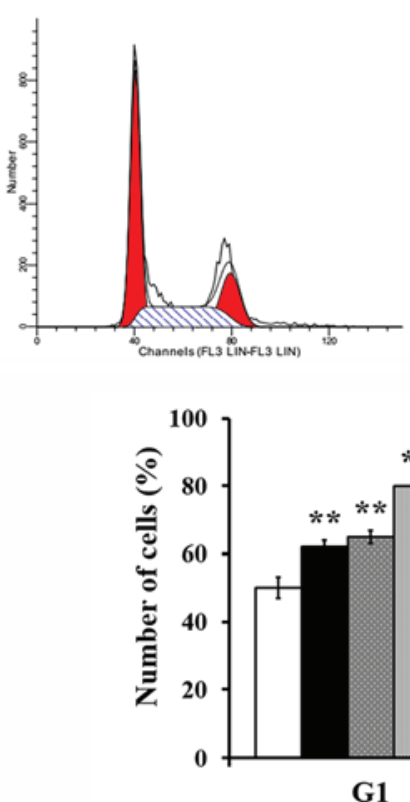

RA+inhibitor NC

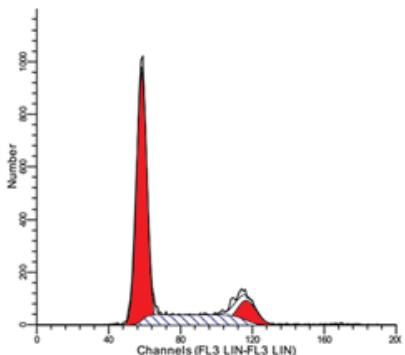

RA+mimic 155

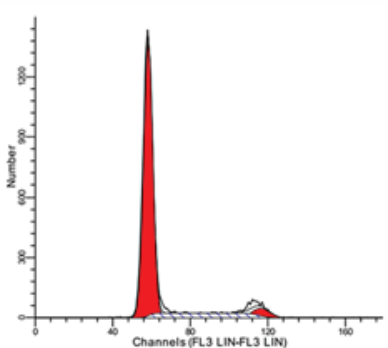

aControl

- RA+mimic NC

aRAtinhibitor NC

QRA+mimic 155

QRA tinhibitor 155

Figure 6. Effect of miR-155 on the cell cycle of LPS-induced synovial fibroblasts. The cell cycle distribution was measured by flow cytometry. Representative histograms are provided and the percentage of cells in each phase of the cell cycle is plotted as the mean \pm standard deviation $(\mathrm{n}=3) .{ }^{* *} \mathrm{P}<0.01$ vs. control group; ${ }^{\# \#} \mathrm{P}<0.01$ vs. RA + mimic NC; ${ }^{\$} \mathrm{P}<0.01$ vs. RA + inhibitor NC. miR, microRNA; RA, rheumatoid arthritis; NC, negative control; mimic 155 , miR-155 mimics.

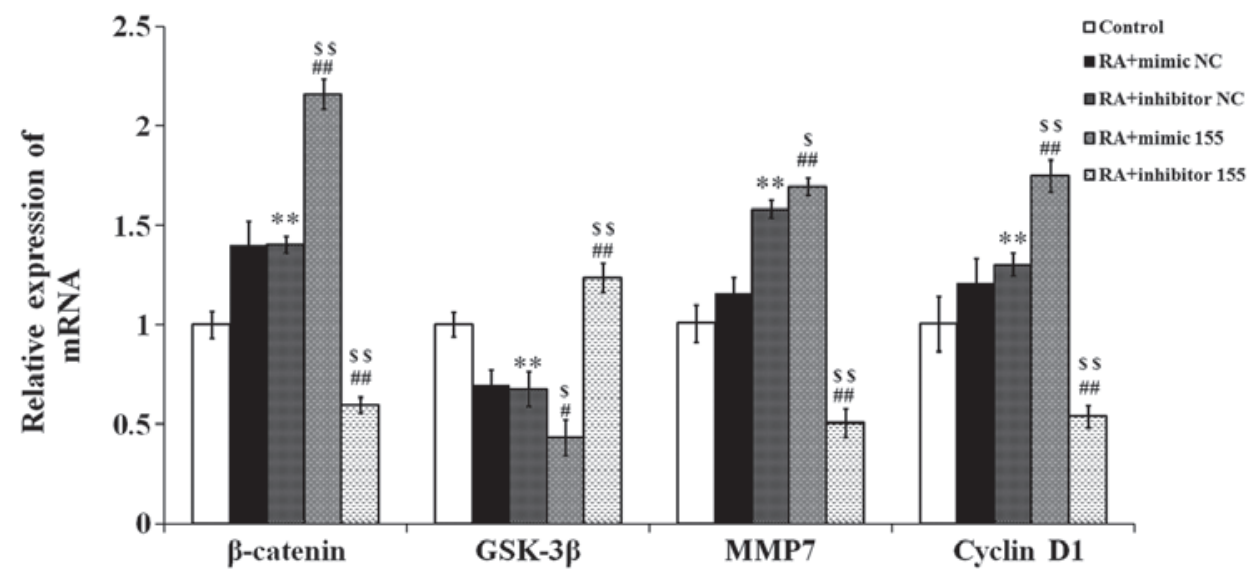

Figure 7. Effect of miR-155 on effector proteins of the Wnt pathway in LPS-induced synovial fibroblasts. The expression of $\beta$-catenin, GSK-3 $\beta$, MMP7 and cyclin D1 was detected by reverse transcription-quantitative polymerase chain reaction. ${ }^{* *} \mathrm{P}<0.01$ vs. control group; ${ }^{*} \mathrm{P}<0.05$, ${ }^{* \# *} \mathrm{P}<0.01 \mathrm{vs}$. RA + mimic $\mathrm{NC}$; ${ }^{\$} \mathrm{P}<0.05$ and ${ }^{\$ S} \mathrm{P}<0.01$ vs. RA + inhibitor NC. miR, microRNA; RA, rheumatoid arthritis; NC, negative control; mimic 155, miR-155 mimics; GSK, glycogen synthase kinase; MMP, matrix metalloproteinase.

a role in clinical and experimental arthritis. Furthermore, the present results suggested that miR-155 inhibits the viability of synovial fibroblasts and induces cell apoptosis and cell cycle arrest. In addition, miRNA elevated the expression of $\beta$-catenin by lowering GSK-3 $\beta$ expression, which activated the Wnt pathway, and enhanced the expression of the target genes cyclin D1 and MMP7. The Wnt signaling pathway regulates cell proliferation, differentiation, adhesion, morphology and motility, as well as inflammation (25). Thus, the present results suggested that miR-155 contributes to inflammation in RA and may be a promising therapeutic target. In order to confirm the hypothesis that miR-155 is a target for RA treatment, miR-155 was inhibited in synovial fibroblasts induced with LPS, and the results indicated that the cell viability was significantly increased, while the apoptotic rate was significantly decreased compared with those in the RA + NC groups. Deregulation of miR-155 in RA monocytes may contribute to the production of pro-inflammatory chemokines by these cells and to their accumulation at sites of inflammation (26). Of note, the present study indicated that inhibition of miR-155 blocks the Wnt signaling pathway in synovial fibroblasts induced with LPS by reducing the expression of $\beta$-catenin and increasing the expression of GSK-3 $\beta$.

In conclusion, the present study demonstrated that miR-155 inhibits RA synovial fibroblast viability and induces apoptosis and cell cycle arrest by regulating the Wnt signaling pathway. It was inferred that miR-155 may be a potential target for RA treatment. 


\section{Acknowledgements}

Not applicable.

\section{Funding}

This study was supported by the innovation fund of Huazhong University of Science and Technology (grant no. 3202754).

\section{Availability of data and materials}

The datasets used and/or analyzed during the current study are available from the corresponding author on reasonable request.

\section{Authors' contributions}

FR designed the experiment and was responsible for the acquisition of funding. HL cultured the cells, performed vector transfection and was a major contributor in writing the manuscript. PL assessed the expression of mRNA using reverse transcription-quantitative polymerase chain reaction analyses. YG analyzed cell apoptosis and cell cycle distribution using flow cytometry. JL contributed to the design of the present study and measured the cell viability using the MTT assay. All authors read and approved the final manuscript.

\section{Ethics approval and consent to participate}

All experimental procedures on animals were approved by the Institutional Animal Care and Use Committee at Tongji Hospital, Tongji Medical College, Huazhong University of Science and Technology.

\section{Patient consent for publication}

Not applicable.

\section{Competing interests}

The authors declare that they have no competing interests.

\section{References}

1. Klareskog L, Catrina AI and Paget S: Rheumatoid arthritis Lancet 373: 659-672, 2009.

2. Firestein GS: Evolving concepts of rheumatoid arthritis. Nature 423: 356-361, 2003

3. Lipsky PE, van der Heijde DM, St Clair EW, Furst DE, Breedveld FC, Kalden JR, Smolen JS, Weisman M, Emery P, Feldmann M, et al: Infliximab and methotrexate in the treatment of rheumatoid arthritis. Anti-tumor necrosis factor trial in rheumatoid arthritis with concomitant therapy study group. N Engl J Med 343: 1594-1602, 2000.

4. Salemi S, Biondo MI, Fiorentino C, Argento G, Paolantonio M, Di Murro C, Malagnino VA, Canzoni M, Diamanti AP and D'Amelio R: Could early rheumatoid arthritis resolve after periodontitis treatment only?: Case report and review of the literature. Medicine (Baltimore) 93: e195, 2014.

5. Ham O, Lee CY, Kim R, Lee J, Oh S, Lee MY, Kim J, Hwang KC, Maeng LS and Chang W: Therapeutic potential of differentiated mesenchymal stem cells for treatment of osteoarthritis. Int J Mol Sci 16: 14961-14978, 2015.

6. Lewis BP, Burge CB and Bartel DP: Conserved seed pairing, often flanked by adenosines, indicates that thousands of human genes are microRNA targets. Cell 120: 15-20, 2005.
7. Kurowska-Stolarska M, Alivernini S, Ballantine LE, Asquith DL, Millar NL, Gilchrist DS, Reilly J, Ierna M, Fraser AR, Stolarski B, et al: MicroRNA-155 as a proinflammatory regulator in clinical and experimental arthritis. Proc Natl Acad Sci USA 108: 11193-11198, 2011.

8. Pauley KM, Satoh M, Chan AL, Bubb MR, Reeves WH and Chan EK: Upregulated miR-146a expression in peripheral blood mononuclear cells from rheumatoid arthritis patients. Arthritis Res Ther 10: R101, 2008.

9. Livak KJ and Schmittgen TD: Analysis of relative gene expression data using real-time quantitative PCR and the 2(-Delta Delta C(T)) method. Methods 25: 402-408, 2001.

10. Roelofs MF, Wenink MH, Brentano F, Abdollahi-Roodsaz S, Oppers-Walgreen B, Barrera P, van Riel PL, Joosten LA, Kyburz D, van den Berg WB and Radstake TR: Type I interferons might form the link between Toll-like receptor (TLR) 3/7 and TLR4-mediated synovial inflammation in rheumatoid arthritis (RA). Ann Rheum Dis 68: 1486-1493, 2009.

11. Gierut A, Perlman H and Pope RM: Innate immunity and rheumatoid arthritis. Rheum Dis Clin North Am 36: 271-296, 2010.

12. Watanabe T, Takahashi N, Hirabara S, Ishiguro N and Kojima T: Hyaluronan inhibits Tlr-4-dependent RANKL expression in human rheumatoid arthritis synovial fibroblasts. PLoS One 11: e0153142, 2016.

13. Andersson AK, Li C and Brennan FM: Recent developments in the immunobiology of rheumatoid arthritis. Arthritis Res Ther 10: 204, 2008.

14. Wang ZC, Lu H, Zhou Q, Yu SM, Mao YL, Zhang HJ, Zhang PC and Yan WJ: MiR-451 inhibits synovial fibroblasts proliferation and inflammatory cytokines secretion in rheumatoid arthritis through mediating p38MAPK signaling pathway. Int J Clin Exp Pathol 8: 14562-14567, 2015.

15. Miao CG, Yang YY, He X, Li XF, Huang C, Huang Y, Zhang L, $\mathrm{Lv} \mathrm{XW}$, Jin Y and Li J: Wnt signaling pathway in rheumatoid arthritis, with special emphasis on the different roles in synovial inflammation and bone remodeling. Cell Signal 25: 2069-2078, 2013.

16. Umar S, Hedaya O, Singh AK and Ahmed S: Thymoquinone inhibits TNF- $\alpha$-induced inflammation and cell adhesion in rheumatoid arthritis synovial fibroblasts by ASK1 regulation. Toxicol Appl Pharmacol 287: 299-305, 2015.

17. Miyaki S and Asahara H: Macro view of microRNA function in osteoarthritis. Nat Rev Rheumatol 8: 543-552, 2012.

18. Karouzakis E, Gay RE, Gay S and Neidhart M: Epigenetic control in rheumatoid arthritis synovial fibroblasts. Nat Rev Rheumatol 5: 266-272, 2009.

19. Ando A, Hagiwara Y, Onoda Y, Hatori K, Suda H, Chimoto E and Itoi E: Distribution of type A and B synoviocytes in the adhesive and shortened synovial membrane during immobilization of the knee joint in rats. Tohoku J Exp Med 221: 161-168, 2010.

20. Philippe L, Alsaleh G, Suffert G, Meyer A, Georgel P, Sibilia J, Wachsmann D and Pfeffer S: TLR2 expression is regulated by microRNA miR-19 in rheumatoid fibroblast-like synoviocytes. J Immunol 188: 454-461, 2012.

21. Qin Y, Chen Y, Wang W, Wang Z, Tang G, Zhang P, He Z, Liu Y, Dai SM and Shen Q: HMGB1-LPS complex promotes transformation of osteoarthritis synovial fibroblasts to a rheumatoid arthritis synovial fibroblast-like phenotype. Cell Death Dis 5: e1077, 2014.

22. Mookherjee N and El-Gabalawy HS: High degree of correlation between whole blood and PBMC expression levels of miR-155 and miR-146a in healthy controls and rheumatoid arthritis patients. J Immunol Methods 400-401: 106-110, 2013.

23. Filkova M, Aradi B, Senolt L, Ospelt C, Vettori S, Mann H, Filer A, Raza K, Buckley CD, Snow M, et al: Association of circulating miR-223 and miR-16 with disease activity in patients with early rheumatoid arthritis. Ann Rheum Dis 73: 1898-1904, 2014.

24. Jin HM, Kim TJ, Choi JH, Kim MJ, Cho YN, Nam KI, Kee SJ, Moon JB, Choi SY, Park DJ, et al: MicroRNA-155 as a proinflammatory regulator via SHIP-1 down-regulation in acute gouty arthritis. Arthritis Res Ther 16: R88, 2014.

25. de Lau W, Barker N, Low TY, Koo BK, Li VS, Teunissen H, Kujala P, Haegebarth A, Peters PJ, van de Wetering M, et al: Lgr5 homologues associate with Wnt receptors and mediate R-spondin signalling. Nature 476: 293-297, 2011.

26. Elmesmari A, Gilchrist D, Fraser A, Brewer J, Mcinnes I and Kurowskastolarska M: The role of miR-155 in monocyte migration in Rheumatoid arthritis, 2012. 